\title{
Effects of colloidal nanosilica on rheological and mechanical properties of fly ash-cement mortar
}

\author{
Peng-kun Hou ${ }^{\text {a,b,*, }}$, Shiho Kawashima ${ }^{\mathrm{b}}$, Ke-jin Wang ${ }^{\mathrm{c}}$, David J. Corr ${ }^{\mathrm{d}}$, Jue-shi Qian ${ }^{\mathrm{a}}$, Surendra P. Shah ${ }^{\mathrm{b}}$ \\ ${ }^{a}$ College of Materials Science and Engineering, Chongqing University, Chongqing 400045, China \\ ${ }^{\mathrm{b}}$ Department of Civil and Environmental Engineering, Northwestern University, Evanston, IL 60208, USA \\ ${ }^{\mathrm{c}}$ Department of Civil, Construction and Environmental Engineering, Iowa State University, Ames, IA 50011, USA \\ ${ }^{\mathrm{d}}$ Department of Civil and Environmental Engineering and Infrastructure Technology Institute, Northwestern University, Evanston, IL 60208, USA
}

\section{A R T I C L E I N F O}

\section{Article history:}

Received 16 March 2012

Received in revised form 22 August 2012

Accepted 23 August 2012

Available online 11 September 2012

\section{Keywords:}

Fly ash

Nanosilica

Rheology

Fluidity

Strength gain

\begin{abstract}
A B S T R A C T
The present study is aimed at investigating the combined effects of colloidal nanosilica (CNS) and fly ash on the properties of cement-based materials. The fresh and hardened properties of mixtures with CNS of $10 \mathrm{~nm}$ size and two Class F fly ashes were evaluated. Results revealed that CNS accelerates the setting of fly ash-cement systems by accelerating cement hydration, while fly ash can offset the reduction in fluidity caused by CNS. The early-age strength gain (before $7 \mathrm{~d}$ ) of fly ash-cement systems was improved by CNS. However, the strength gain of mixtures with CNS diminished at later ages (after $28 \mathrm{~d}$ ), where strength was eventually comparable to or exceeded by mixtures without CNS. Results showed that lack of $\mathrm{Ca}(\mathrm{OH})_{2}$, which results from the high pozzolanic reactivity of CNS at early ages, and the hydration hindrance effect of CNS on cement at later ages can be the critical reasons.
\end{abstract}

(c) 2012 Elsevier Ltd. All rights reserved.

\section{Introduction}

Fly ash is the most widely used industrial waste product in the cement and concrete industry. It introduces many advantages, including lower cost, increased flowability [1], increased durability, and improved strength gain at later ages. However, delays in early-age strength gain and setting times are considered to be major drawbacks [2-4]. Although these delays are desirable for some applications, such as in mass concrete [5], in most cases this delay is undesirable. To compensate for this shortcoming, many methods have been explored to accelerate the early-age hydration of fly ash-cement systems, including mechanical grinding [6], chemical activation [7], mechanochemical treatment [8] and hydrothermal treatment $[9,10]$.

In recent years, nanosilica has been introduced into cement and concrete research. Multiple studies have shown that even at small dosages, nanosilica can improve the mechanical properties of cementitious materials [11-13]. According to Nazari and Riahi, a $70 \%$ compressive strength improvement of concrete can be achieved with an addition of $4 \%$ nanosilica by mass of cement [11]. In a separate study, Shih et al. showed that a $0.6 \%$ colloidal nanosilica addition can improve the compressive strength of

\footnotetext{
* Corresponding author at: College of Materials Science and Engineering, Chongqing University, Chongqing 400045, China. Tel.: +86 2365126109.

E-mail address: pkhou@163.com (P.-k. Hou).
}

cement paste by $43.8 \%$ [12]. And Li et al. found that when $3 \%$ and $5 \%$ nanosilica were added to plain cement mortar, compressive strength increased by $13.8 \%$ and $17.5 \%$ at $28 \mathrm{~d}$, respectively [13]. For the high pozzolan replacement cementitious materials, Zhang et al. $[14,15]$ found that the physical and mechanical properties of high-volume fly ash/slag systems can be greatly enhanced. Li's results [16] showed that nanosilica improved the compressive strength of $50 \%$ fly ash replacement concrete by $7 \%$ after 2 years hydration.

There are two important problems to be considered regarding using nanosilica powder. One important consideration is dispersion. Intensive mechanical/ultrasonic dispersion and/or surface treatment were applied in the aforementioned studies. Failing to achieve proper dispersion will cause a negative effect on the strength evolution process [11]. Another problem that should be taken into consideration in using nanosilica is the decrease in fluidity, due to its high surface area to volume ratio and increased water demand. In considering the two constituents (fly ash and nanosilica), the benefits of each material can help counteract the shortcomings of the other: reactive nanosilica can improve the early-age mechanical properties while fly ash can improve flowability. Regarding the issue of dispersion, water-based colloidal nanosilica (CNS) can be used in place of nanosilica powder.

Although it has been well-documented that nanosilica can significantly improve the early-age mechanical properties of cementitious materials and the improvements are attributed to the 
Table 1

Properties of colloidal nanosilica.

\begin{tabular}{llllll}
\hline CNS & $\begin{array}{l}\text { Average } \\
\text { particle } \\
\text { size }(\mathrm{nm})\end{array}$ & $\begin{array}{l}\text { Solid } \\
\text { content } \\
(\text { wt.\% })\end{array}$ & $\begin{array}{l}\text { Viscosity } \\
(\mathrm{Pa} S)\end{array}$ & $\mathrm{pH}$ & $\begin{array}{l}\text { Solid } \\
\text { density } \\
\left(\mathrm{g} / \mathrm{cm}^{3}\right)\end{array}$ \\
\hline CNS-10 & 10 & 30 & 8 & 10.5 & 2.39 \\
\hline
\end{tabular}

nucleation seeding effect and pozzolanic reactivity of the nanoparticle [17], there are some results that show nanoparticles can have an adverse effect on later-age strength gain $[11,18,19]$. Very recently, Berra et al. [20] investigated the influence of mixing procedures on the rheological and mechanical properties of nanosilica-added cement-based materials and stated that the instantaneous formation of gel upon nanosilica's meeting cement solution and superplasticizer would adversely affect its influence on the property evolution of cement-based materials. However, very few studies regarding the combined effects of CNS and fly ash on the fresh properties and the effects of nanoparticles on later-age mechanical properties have been completed $[21,22]$.

In this work, the effects of CNS on the fresh and hardened properties (early and long-term) of fly ash cementitious materials were studied. Factors affecting these properties, such as fly ash class/ replacement ratio and CNS dosage were investigated. Moreover, reasons governing the mechanical property evolution characteristics of CNS-added high-fly ash replacement cementitious materials were studied.

\section{Experimental}

\subsection{Raw materials}

The CNS is produced by the sol-gel technique. In this technique, the nanoparticles are formed by the condensation and polymerization of $\mathrm{SiO}_{2}$ monomers that form through hydrolysis of trimethylethoxysilane or tetraethoxysilane - the commonly used precursors for synthesis of nanosilica. Eq. (1) can be used to summarize the nanosilica synthesis process. When drying is applied to the produced gel, a nanosilica powder can be obtained [19]. In this study, a water-based and sodium-stabilized CNS with an average particle size of $10 \mathrm{~nm}$ (CNS-10) was used. The basic properties, as provided by the manufacturers of the CNS, are listed in Table 1 [23]. Transmission electron microscopy (TEM) images of CNS-10 in Fig. 1 show that although most of the CNS particles are evenly distributed, some are still agglomerated, which may be due to the sample preparation technique
Table 2

Physiochemical properties of fly ash and cement.

\begin{tabular}{|c|c|c|c|}
\hline Materials & Type I cement & Fly ash 1 & Fly ash 2 \\
\hline $\mathrm{SiO}_{2}$ & 20.2 & 46 & 53.5 \\
\hline $\mathrm{Al}_{2} \mathrm{O}_{3}$ & 4.7 & 17.8 & 25.2 \\
\hline $\mathrm{Fe}_{2} \mathrm{O}_{3}$ & 3.3 & 18.2 & 7.2 \\
\hline $\mathrm{SO}_{3}$ & 3.3 & 2.59 & 0.32 \\
\hline $\mathrm{CaO}$ & 62.9 & 8.4 & 1.46 \\
\hline $\mathrm{MgO}$ & 2.7 & 0.95 & 1.43 \\
\hline $\mathrm{Na}_{2} \mathrm{O}$ & 1 & 0.59 & 0.49 \\
\hline $\mathrm{K}_{2} \mathrm{O}$ & 1 & 2.16 & 3.51 \\
\hline LOI & 1.1 & 1.49 & 4.87 \\
\hline Total & 98.2 & 98.2 & 98 \\
\hline Water requirement ratio $\star / \%$ & 1 & 93 & 98 \\
\hline Density $/\left(\mathrm{g} / \mathrm{cm}^{3}\right)$ & 3.10 & 2.30 & 2.26 \\
\hline
\end{tabular}

Water requirement ratio $\star$ : water required (compared to that of plain mortar) for $30 \mathrm{wt} . \%$ fly ash replaced cement mortar to achieve the same fluidity with that of plain mortar.

$n \mathrm{Si}\left(\mathrm{OC}_{2} \mathrm{H}_{5}\right)_{4}+2 n \mathrm{H}_{2} \mathrm{O} \stackrel{\mathrm{C}_{2} \mathrm{H}_{5} \mathrm{OH}_{\rightarrow} \mathrm{NH}_{3}}{\rightarrow} n \mathrm{SiO}_{2}+4 n \mathrm{C}_{2} \mathrm{H}_{5} \mathrm{OH}$

A type I Portland cement with a Blaine fineness of $385 \mathrm{~m}^{2} / \mathrm{kg}$ and a $28 \mathrm{~d}$ compressive strength of $45.1 \mathrm{MPa}$ was used in this study. Two fly ashes (Table 2 ), which vary greatly in calcium oxide content, were used: $8.4 \%$ for fly ash 1 (FA1) and $1.46 \%$ for fly ash 2 (FA2). Although according to ASTM C618 [24] both fly ashes fall under class $\mathrm{F}$, the difference in aluminosilicate/ferrite content $\left(\mathrm{SiO}_{2} \%+\mathrm{Al}_{2} \mathrm{O}_{3} \%+\mathrm{Fe}_{2} \mathrm{O}_{3} \%\right)$ is significant, indicating that the vitreous constituents that are the source of pozzolanic reactivity are different. This assumption was verified by X-ray diffraction (XRD) results, shown in Fig. 2. It can be seen that the diffusive diffraction background of FA2 is greater than that of FA1 in the two theta range of $20-35^{\circ}$, in which the main phases are aluminosilicates. This indicates that the aluminosilicates amorphous phase content of FA2 is greater. This difference should be reflected by the pozzolanic reactivity of the fly ashes [4]. Fig. 2 also indicates that there are more crystalline phases in FA1 than in FA2. This may be due to the difference in $\mathrm{CaO}$ content, which can greatly influence the pozzolanic reactivity [25].

The water demand ratios of FA1 and FA2 are 93\% and 98\%, respectively. It is shown in the scanning electron microscopy (SEM) images of the fly ashes (Fig. 3) that FA1 are round in shape and contain very few impurities, while FA2 contains some porous particles. From the LOI values listed in Table 2, as well as the morphological characteristics of the fly ash components, it is deduced that the porous substance is carbon [26]. The water demand ratio and SEM images of the fly ashes suggest that FA1 has a higher water reducing effect than FA2. Other parameters of the raw materials are also shown in Table 2.
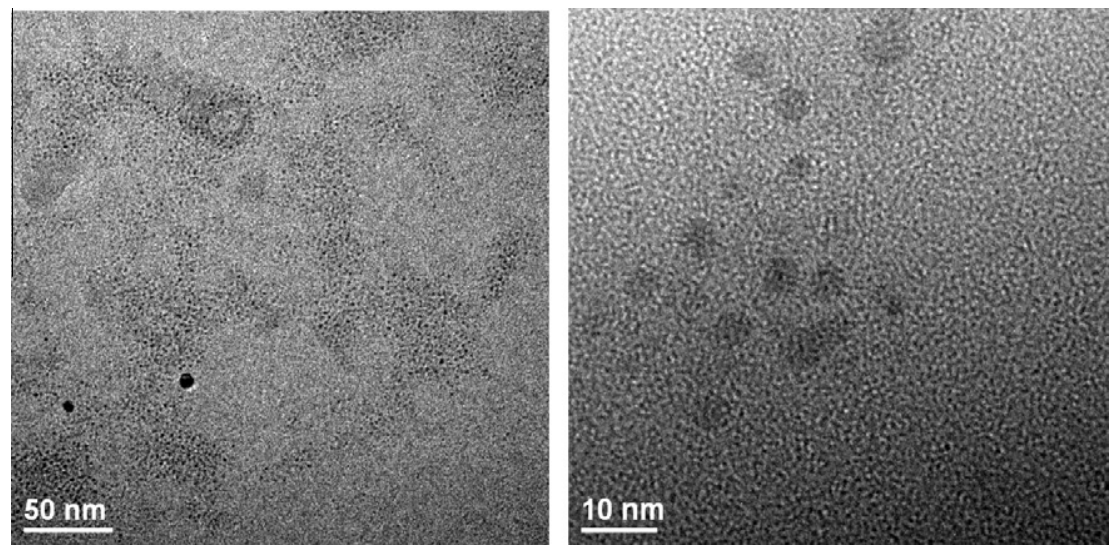

Fig. 1. TEM images of CNS-10. 


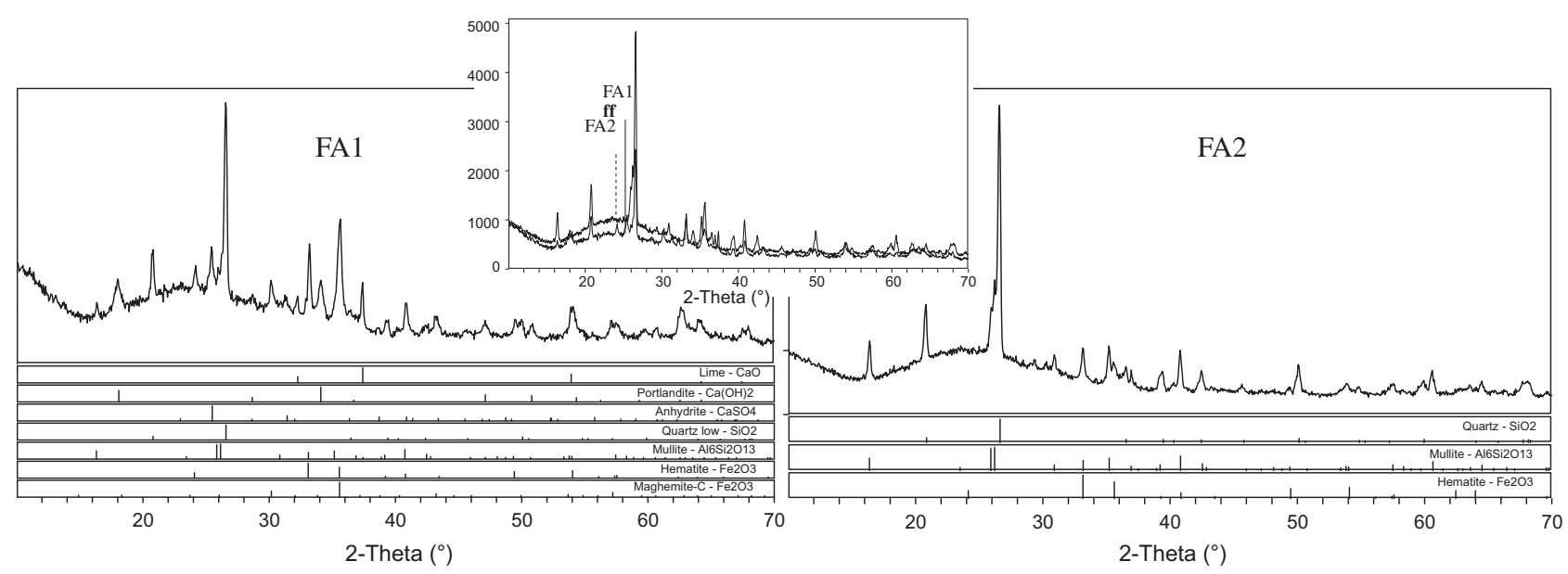

Fig. 2. XRD patterns of fly ashes.

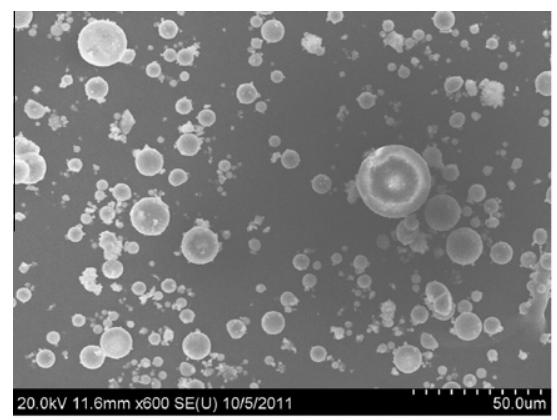

FA1

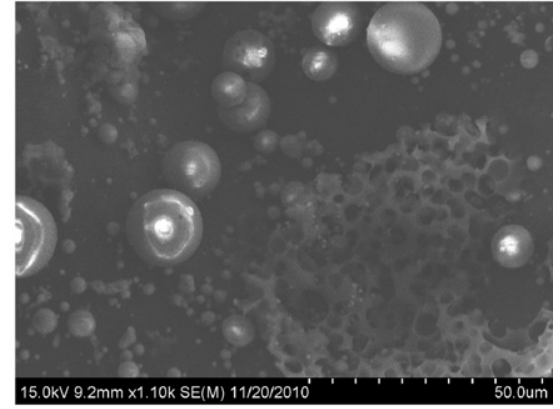

FA2

Fig. 3. SEM images of fly ashes.

\subsection{Mixture proportions}

Three dosages of CNS addition ( $0 \%, 2.25 \%$ and $5 \%$ (solid state) by mass of binder) and three levels of cement replacement with fly ash $(20 \%, 40 \%$, and $60 \%$ by mass) were used. Water to binder ( $w /$ $b$ ) ratios of 0.41 and 0.35 by mass were used to investigate rheological and setting properties, respectively. (When calculating the $w / b$ ratio, the water content of the CNS was appropriately considered.)

A $w / b$ ratio of 0.5 and a binder-to-sand ratio of $1 / 3$ were used for all mortar mixtures. Raw materials were dry mixed for $1 \mathrm{~min}$ at low speed to obtain a homogenous mixture, wet mixed at low speed for another minute, and then mixed at medium speed for $3 \mathrm{~min}$. As CNS was in a water base, it was hand-stirred in the mixing water prior to adding the other materials, to achieve a homogeneous solution and the small strength variation of replicate samples (shown in the results section) indicated that a homogeneous mixing has been achieved.

To sustain a constant water-to-binder ratio, the replacement of fly ash and addition of CNS were on a mass basis, which, however, may introduce differences in the water volume fractions in the mixtures with the addition of CNS due to its density difference to that of the other powders. As calculated in Ref. [22], the difference in water volume fraction of mixtures with and without CNS at the same fly ash replacement ratio is very slight; the influence of water volume fraction differences on the properties of mixtures of the same fly ash replacement ratio with and without CNS is therefore considered to be negligible. However, the difference in water volume fraction between the control mixture without fly ash and those with fly ash is more significant, due to the specific gravity of the cement being about 3.1, while those of the fly ashes are near 2.3.

\subsection{Setting time}

ASTM C191 [27] was followed and a manual Vicat apparatus was used to determine the initial and final setting time of pastes. Setting times were determined from the time-Vicat needle penetration depth curve.

\subsection{Shear rheology and fluidity}

A temperature-controlled rheometer with a coaxial cylinder geometry was used to measure the shear rheological properties of pastes. The inner and outer cylinders were $10 \mathrm{~mm}$ and $10.85 \mathrm{~mm}$ in diameter, respectively. Although the 'wall slip' effect of the coaxial cylinder rheometer will affect the accuracy of the absolute rheological values [28], the comparison of the relative rheological data can still adequately reflect the effect of CNS on the rheological properties of the system. Plastic viscosities and yield stresses were obtained using the Bingham model:

$\tau=\tau_{0}+\mu_{p} \gamma$

where $\tau$ is the shear stress, $\tau_{0}$ is the yield stress, $\mu_{p}$ is the plastic viscosity and $\gamma$ is the shear rate. In the previous study, it was found that after mixing for $8 \mathrm{~min}$, cementitious pastes would acquire a stable shear strain-stress curve. So in the real tests, the raw materials were first dry-mixed for $1 \mathrm{~min}$ and then wet-mixed for $8 \mathrm{~min}$. 


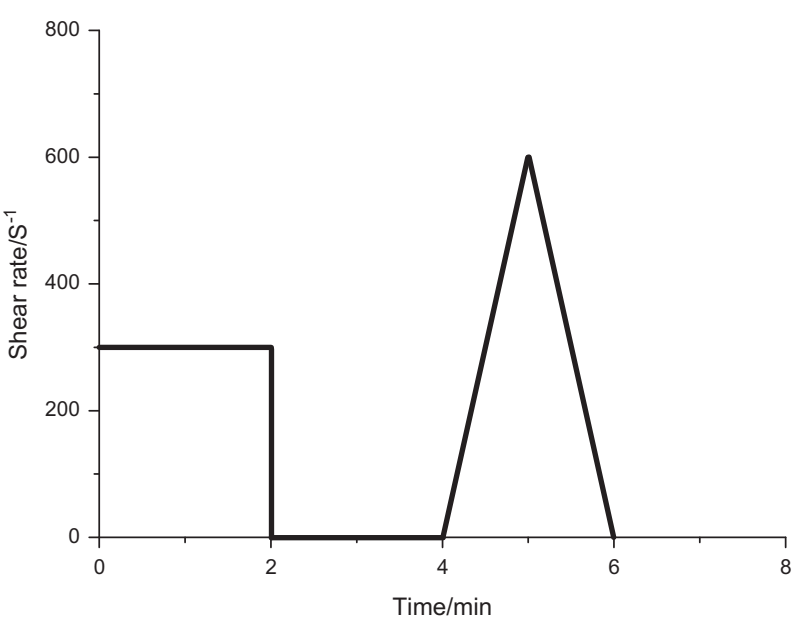

Fig. 4. Shear rheological protocol.

The CNS was first hand-stirred in the mixing water to facilitate dispersion. The shear rheological protocol and typical flow curve obtained are given in Figs. 4 and 5. The coefficients of variation of the plastic viscosities and yield stress of three replicate samples were about $10-15 \%$ and $20 \%$, respectively.

Following ASTM C230 [29], the fluidity of mortar was measured using a flow table.

\subsection{Compressive strength}

ASTM C109 [30] was followed to measure the compressive strength of mortar by using a $4448 \mathrm{kN}$ MTS hydraulic test machine. For each mixture at each age, three $\Phi 5.08 \mathrm{~cm} \times 10.16 \mathrm{~cm}$ cylindrical samples were tested and the average value was taken to be the representative strength. To evaluate the effect of CNS on the strength evolution of fly ash-cement systems, the compressive strength ratio at each curing age was calculated using the following equation:

$R(\%)=100 * f_{i} / f_{c}$

where $R$ is compressive strength ratio, \%, $f_{i}$ is compressive strength of fly ash mortar with various dosages of CNS, and $f_{c}$ is compressive strength of plain cement mortar.

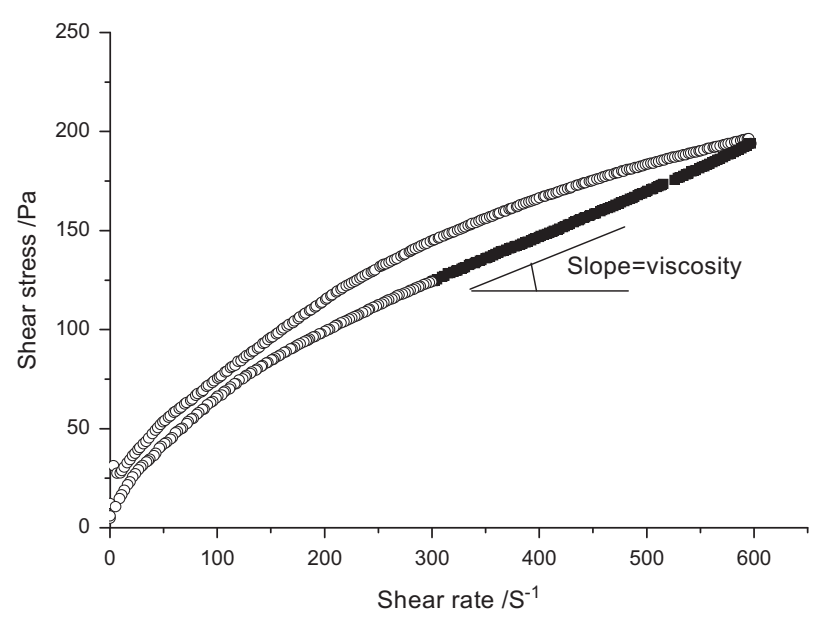

Fig. 5. Typical hysteresis loop for cement paste and Bingham plastic viscosity calculated using the slope of the down curve from 600 to $300 \mathrm{~S}^{-1}$.
An $R$ value greater than $100 \%$ indicates a higher strength than that of plain cement mortar. The slope of the $R$ curve shows the strength evolution rate compared to that of plain mortar. By comparing $R$, the influence of fly ash and CNS on strength evolution can be determined. All samples were water-cured at room temperature beginning at $24 \mathrm{~h}$ after casting.

\subsection{Hydration degree of cement at later ages}

Image analysis of graphs obtained from backscattered electron microscopy technique (BSE, Hitachi S-3400) was used to evaluate the hydration degree of cement paste at later ages. The intensity of the BSE signal is mainly a function of the average atomic number of the local area of the sample. During hydration, water is incorporated into unhydrated cement particles and lowers the average atomic number of the hydrates, and thus strong imaging contrast of unreacted (anhydrous) and reacted component (hydrates) can be obtained [31] and the hydration degree can be evaluated through image analysis.

Before testing, a thin sample section of approximately $5 \mathrm{~mm}$ was cut out of the specimen cast in a $2 \mathrm{~cm} \times 2 \mathrm{~cm} \times 8 \mathrm{~cm}$ mold and mounted on a metal sample holder for polishing. Samples were polished using silicon carbide paper of gradations $22 \mu \mathrm{m}$, $14.5 \mu \mathrm{m}$, and $6.5 \mu \mathrm{m}$, and the polishing time of each step was $5 \mathrm{~min}$. In the final step, the polished samples were ultrasonically cleaned in water for $1 \mathrm{~min}$ using a bath sonicator to remove polishing debris from the sample surface. Then, the sample was soaked in acetone for $1 \mathrm{~d}$ before being vacuum-dried at $50{ }^{\circ} \mathrm{C}$ for $12 \mathrm{~h}$. Samples were coated with $20 \mathrm{~nm}$ of gold to provide a conductive surface. To accurately evaluate the hydration degree, five BSE images were taken to do image analysis and they were averaged as the representative value of each sample. At the same time, the smallest magnification of $100 \mathrm{X}$ was used to obtain an image with the largest practical field of view.

\section{7. $\mathrm{Ca}(\mathrm{OH})_{2}$ content}

Thermogravimetric analysis (TGA, TGA/sDTA 851) was carried out to measure the $\mathrm{Ca}(\mathrm{OH})_{2}$ content of samples. The weight loss between $440{ }^{\circ} \mathrm{C}$ and $510^{\circ} \mathrm{C}$ was considered to be due to the decomposition of $\mathrm{Ca}(\mathrm{OH})_{2}$. Before measuring, powder samples were oven-dried at $105^{\circ} \mathrm{C}$ for $4 \mathrm{~h}$.

\subsection{Rate of hydration}

The hydration temperature was measured by a semi-adiabatic calorimeter to assess the effect of CNS on the hydration heat of cement pastes. Samples were prepared at a constant $w / b$ ratio of 0.4 by mass, with $100 \mathrm{~g}$ of cement and $40 \mathrm{~g}$ of mixing water at a temperature of $27^{\circ} \mathrm{C}$. Mixtures were cast in $\Phi 5 \mathrm{~cm} \times 10 \mathrm{~cm}$ plastic cylinders within 3 min after initial cement and water contact. The sample was then covered, placed in the calorimeter, and the temperature of the sample was recorded every $3 \mathrm{~min}$ for $20 \mathrm{~h}$.

\section{Results and discussions}

\subsection{Setting time}

Fig. 6 shows the influence of CNS on the hardening of fly ashcement pastes. It is apparent that CNS greatly shortened the initial and final setting time of all pastes. When CNS was added, the initial and final setting time of fly ash-cement pastes were significantly shortened. Although fly ash delays the hardening of pastes, the addition of CNS can greatly offset this effect. A great effect of 

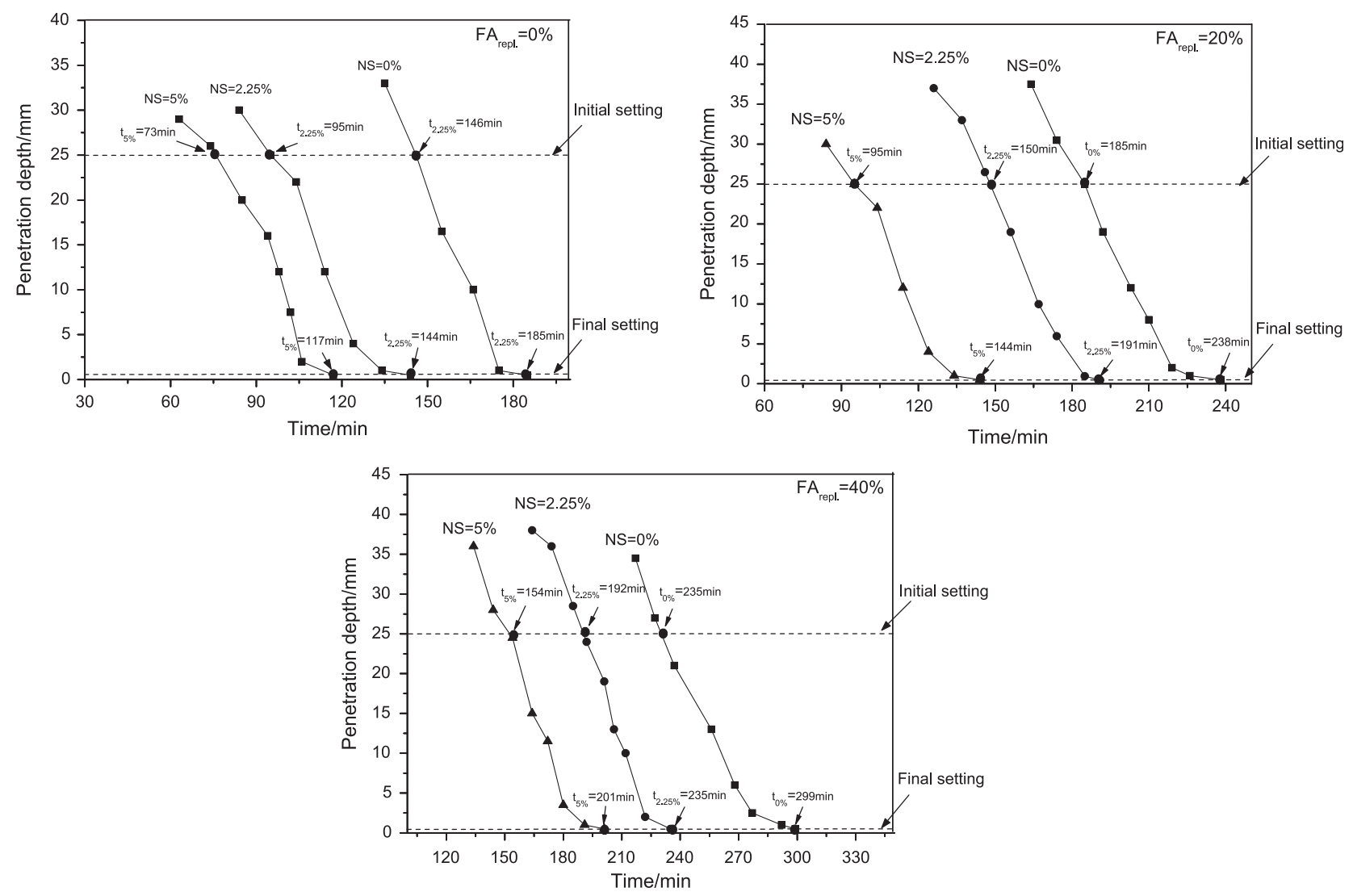

Fig. 6. Influence of CNS on the hardening of FA1 pastes.

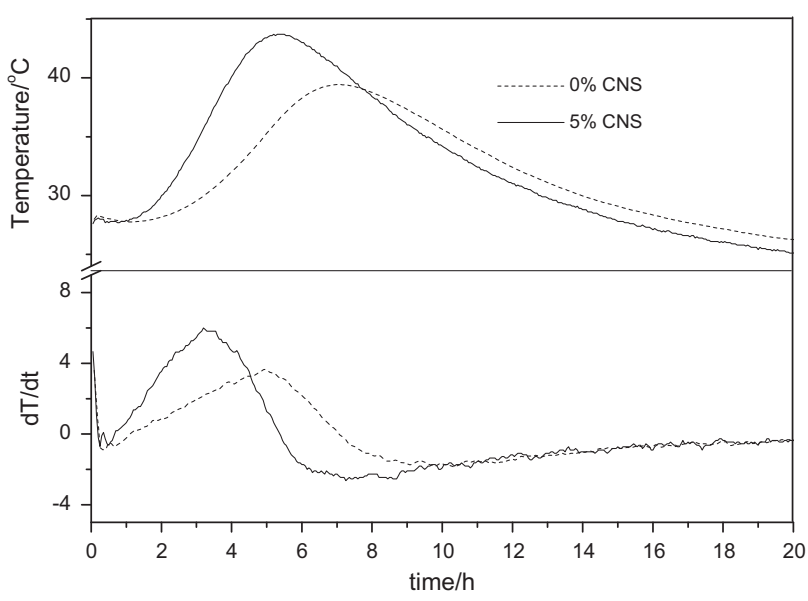

Fig. 7. Effect of CNS-10 on cement hydration.

nanosilica on the reduction of setting times of fly ash-cement systems was also obtained by other researchers [14,15].

The shortened setting time of cement-fly ash pastes with CNS can be accounted for by the accelerating effect of the CNS on cement hydration [17]. It was found that the dissolution and precipitation processes of cement particles and hydrates were accelerated by CNS at the beginning of reaction, and thus the hydration and hardening of cementitious materials were enhanced [21]. The acceleration effect was demonstrated in Fig. 7 in that both the hydration temperature peak and hydration rate (shown as the $1 \mathrm{st}$ Dev. of the temperature curve) were increased.

\subsection{Rheological properties}

The viscosities of fly ash-cement pastes with and without CNS-10 are shown in Fig. 8. For the plain cement paste without CNS, the addition of fly ash increased viscosity, but it did not increase proportionally with the replacement ratio. For all mixtures, the addition of CNS led to an increase in viscosity. The increase is more significant for plain cement pastes, where the viscosity of the $5 \%$ CNS paste was 4.3 times that of the $0 \%$ CNS paste. But, for fly ash-cement pastes, the viscosities of the 5\% CNS pastes were about 2.5 times greater than those of the $0 \%$ CNS pastes. It is also shown that the viscosity of fly ash-cement paste with CNS increased almost linearly with CNS dosage. For plain cement paste, however, the increase in viscosity was more marked, being between $2.25 \%$ and $5 \%$. Other work [32] showed only a slight increase in viscosity when CNS dosage was within $2.5 \mathrm{wt} . \%$, as well. Furthermore, it is shown in Fig. 8 that the viscosities of the 5\% CNS FA1 cement pastes were almost the same as that of the $5 \%$ CNS cement paste. For FA2 cement pastes, these values were lower. To explore the reason for the difference of the effects of CNS on the viscosity evolution of the pastes, the CNS adsorption behaviors of the two fly ashes were studied. This behavior was studied through measurement of the solid concentration of a CNS solution of known concentration after it has been mixed, stirred and centrifuged within a fly ash solution with a fly ash-towater mass ratio of 0.5 . The CNS adsorption capacity of fly ash was determined as the CNS concentration loss after these processes. It is shown in Fig. 9 that little CNS was adsorbed by FA1, while more than $40 \%$ was absorbed by FA2. This may be due to the differences of particle size distribution, morphology, and mineralogy of the two fly ashes. The adsorption of CNS on fly ash surfaces may lead to a more serious agglomeration of 

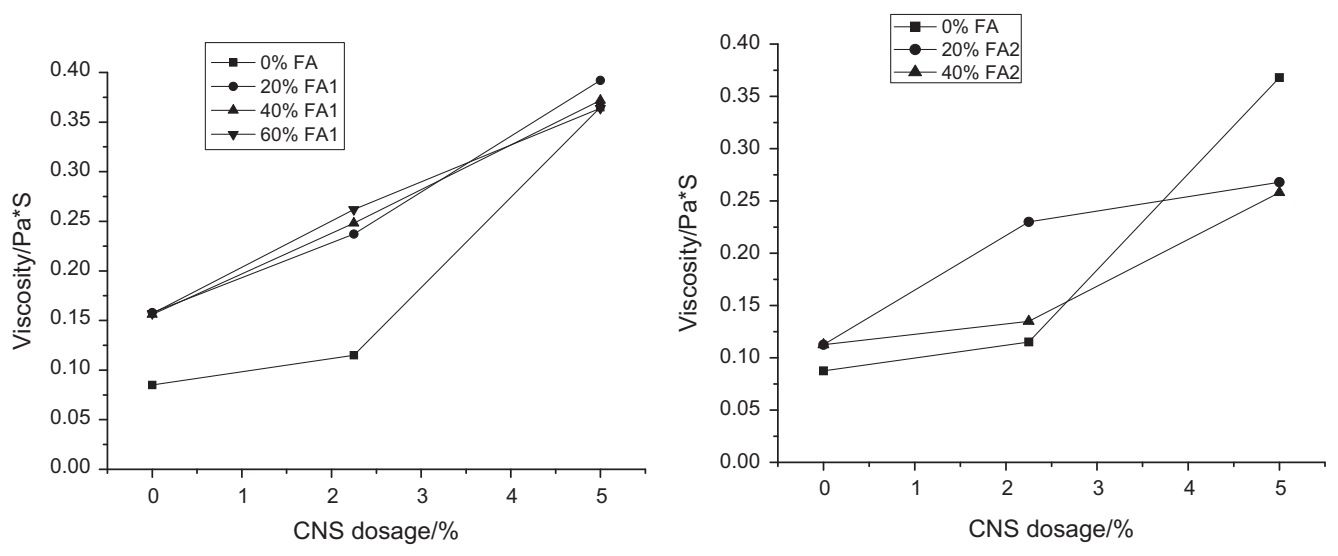

Fig. 8. Effects of CNS-10 on the viscosity of the pastes $(w / b=0.41)$.

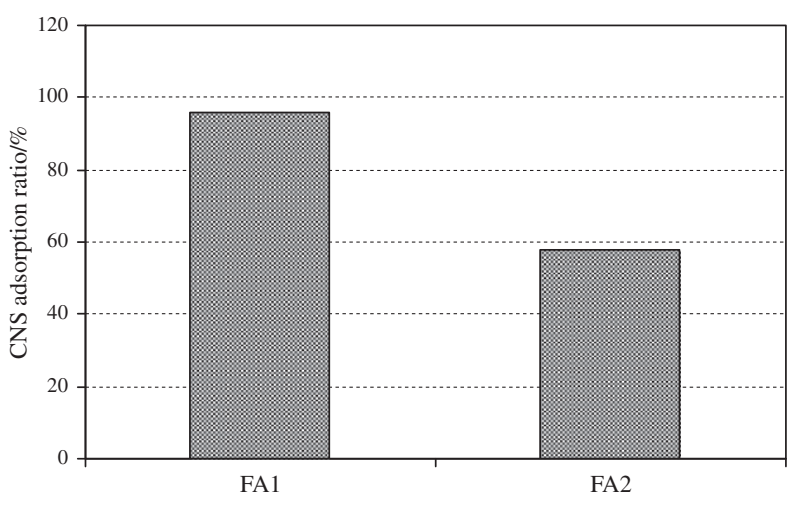

Fig. 9. CNS adsorption capacities of fly ashes.

the particles and a bigger floc size, which was reported as a factor enhancing the viscosity of the materials [33,34].

The influences of CNS on the yield stress of the fly ash cement pastes are shown in Fig. 10. It is shown that for each mixture proportion the addition of CNS leads to an increase of the yield stress. For example, the yield stresses of 5\% CNS-added FA1 pastes are about six times that of the $0 \%$ CNS paste. The yield stress reflects the interparticle forces bonding the particles. As CNS adsorbs water, the particle interlocking becomes greater and the yield stress increases [35]. When comparing the yield stress of fly ash pastes with those of plain cement pastes, it is shown that for most cases, the yield stress of fly ash cement paste is smaller than that of plain cement paste and the higher replacement ratio of fly ash the smaller the value. This is due to the hydraulic-inertness and lack of flocculation of the fly ash particles, which decreases the interparti- cle bond of the pastes. The higher yield stresses of $2.25 \%$ CNSadded FA1 pastes than that of plain cement paste can be due to the high CNS adsorption capacity of FA1. Fig. 10 also reveals that the increases of yield stresses of the two fly ash pastes with the addition of CNS are different and this may be due to the difference of the CNS-adsorption characteristics of the two fly ashes as noted previously.

\subsection{Mortar fluidity}

The effect of CNS dosage on the fluidity of fly ash-cement mortars is shown in Fig. 11. For FA1 mixtures, the fluidity increased with fly ash replacement. However, when CNS was used, the fluidity was greatly decreased. The greater the amount of CNS, the greater is the reduction in fluidity. A $25 \%$ decrease in slump flow was seen in both FA1 and FA2 mixtures when $5 \%$ CNS was added. The reduction in fluidity can be attributed to the increased water demand of the CNS.

It is also shown in Fig. 11 that the fluidity of both fly ash mortars increased with the increase of fly ash dosage, regardless of CNS addition. With the same replacement ratio, the plain FA1 mortar had a higher fluidity than the FA2 mortar and this is due to its greater water reducing effect. When CNS was added, the fluidity reduction was more significant for FA1 mortars. For example, for the $20 \%$ fly ash-replaced mortar, when $5 \%$ CNS was added, FA1 mortar fluidity decreased from $205 \mathrm{~mm}$ to $125 \mathrm{~mm}$, while for FA2 mortar, a smaller reduction, from $195 \mathrm{~mm}$ to $130 \mathrm{~mm}$ can be seen. This may also be due to the difference of CNS adsorption capacity of these two fly ashes. From the above results, it can be seen that fly ash can offset the decrease in flowability of mortar caused by the addition of CNS.
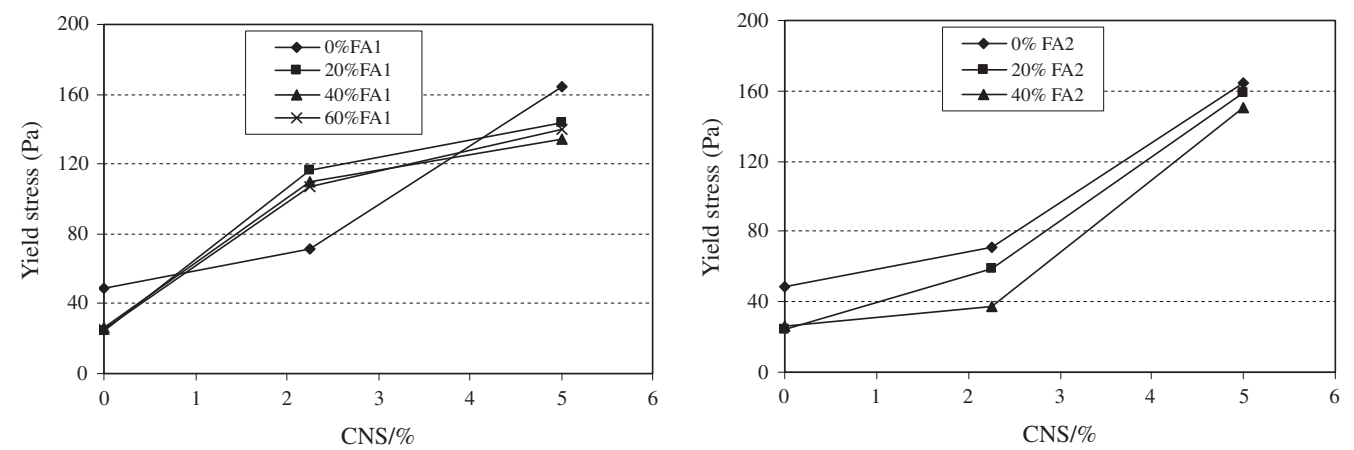

Fig. 10. Effects of CNS-10 on the yield stress of the pastes $(w / b=0.41)$. 

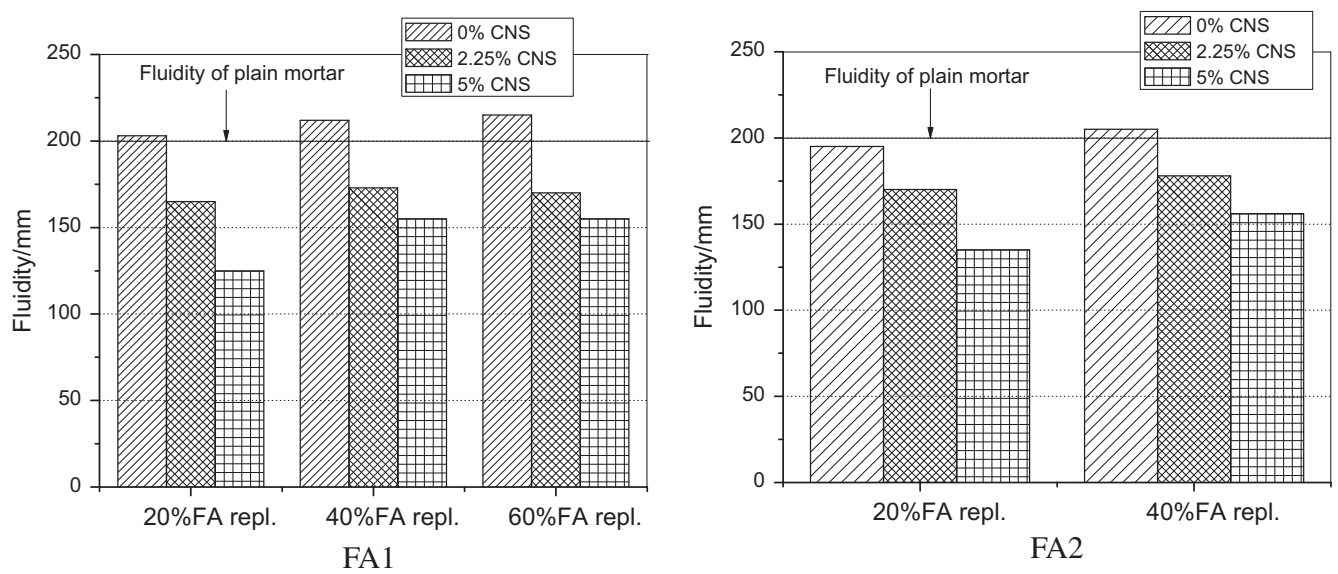

Fig. 11. Effects of CNS on the fluidity of fly ash mortar.
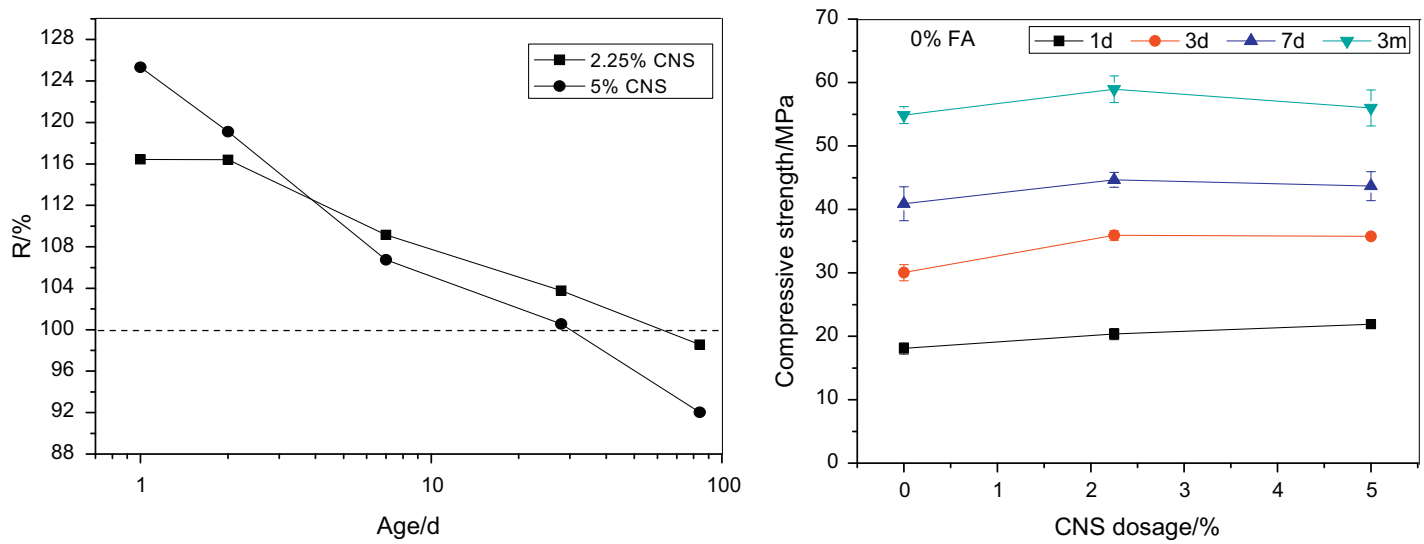

Fig. 12. Influence of CNS on the mechanical properties of plain cement mortar.

\subsection{Mortar strength development}

\subsubsection{CNS-cement mortar strength}

The effect of CNS on the compressive strength gain of plain cement mortar is shown in Fig. 12. The compressive strength ratios of both $2.25 \%$ and $5 \%$ CNS mortars were higher than those of control mortar specimens for ages up to $28 \mathrm{~d}$ of curing, showing that CNS can improve the mechanical properties of plain cement mortar. This is due to the hydration acceleration effect of CNS on cement and the pozzolanic reaction of CNS, as well-documented. It is also shown in Fig. 12 that the strength improvement decreased with time. At $28 \mathrm{~d}$, the $0 \%$ and 5\% CNS mortars exhibited comparable compressive strengths. However, at 3 months, the compressive strength of the $5 \%$ CNS mortar was lower than that of the plain mortar. Although similar results were obtained $[11,18,19]$, no specific research was conducted to explore the reason. This work investigated the effect of CNS on the hydration of cement of a practical dosage. The hydration degree of the cement at an age of 3 months was evaluated by BSE image analysis as shown in Fig. 13: the white particles are the unhydrated cement particles [31]. It is shown that the unhydrated cement particles of the $0 \%$ and $5 \%$ CNS-added cement pastes occupy $3.7 \%$ and $6.4 \%$ of the entire image area after 3 months hydration, respectively, which implies that cement hydration at later ages is hindered in

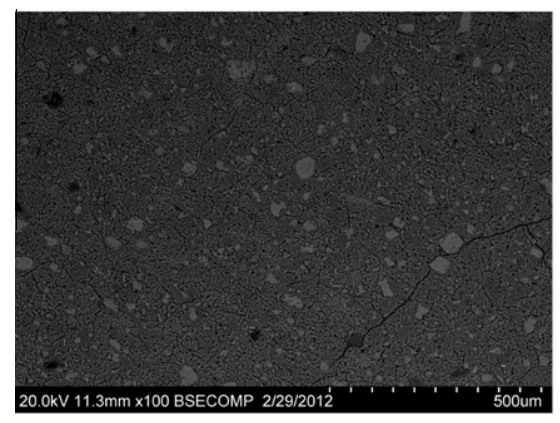

$0 \% \mathrm{CNS}$

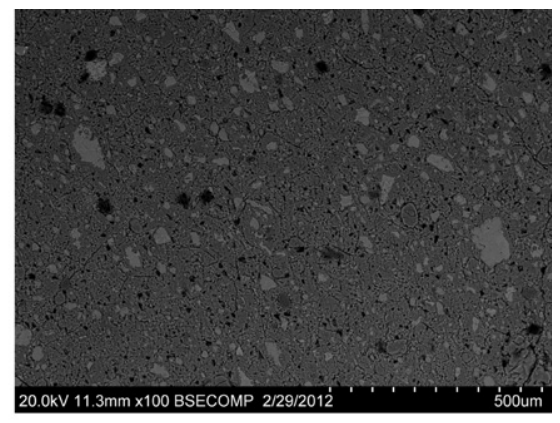

$5 \% \mathrm{CNS}$

Fig. 13. BSE images of cement pastes without/with nanoSiO $\mathrm{S}_{2}$ at 3 months. 

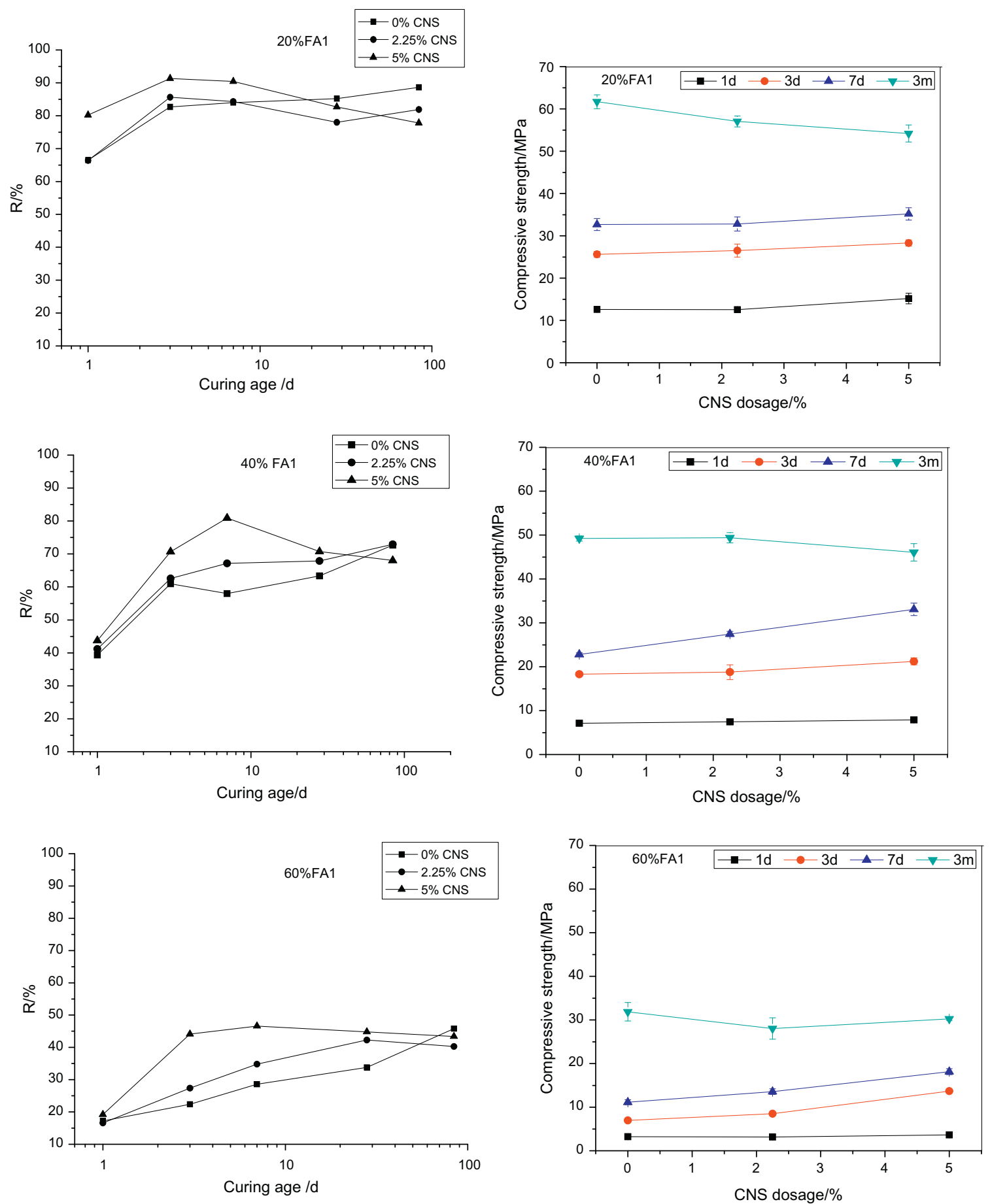

Fig. 14. Effects of CNS-10 $\mathrm{nm}$ on the compressive strength ratio of FA1 cement mortar

CNS-added systems. A coating of hydrates has been observed on unhydrated cement particles of $23 \% \mathrm{CNS}$-added $\mathrm{C}_{3} \mathrm{~S}$ paste, which is considered to be less permeable and hinders $C_{3} S$ hydration at later ages [36]. This may be the reason why there is an optimal nanoparticle dosage in cementitious materials [11]. From the perspective of relieving the hydration hindrance effect of nanoparticles on cement, it seems better to use a finer cement. Kontoleontos et al. [37] studied the effects of nanosilica on the mechanical properties of mortars prepared by ultra-fine cement and results showed that the compressive strength enhancement trend keeps increasing within $28 \mathrm{~d}$, but the longer age properties were unknown. It was also revealed in Fig. 12 that the dosage of nanoparticle should not be high when the property enhancement at early ages is not the primary concern to ensure that no significant hydration hindrance effect occurs at later ages. More fundamentally, nanoindentation results obtained by Zyganitidis [38] showed that the additions of $0.3 \%$ and $0.5 \%$ nanosilica powder resulted in a slight reduction of elastic modulus. However, some contrary results were obtained by Gaitero [39] and Mondal [40]. More investigations are necessary to determine the effects of CNS on cement hydration and the gel properties, especially at later ages.

When compared to plain cement mortar, fly ash replacement cementitious materials are different in physical and chemical properties, hydration characteristics, etc. The influence of CNS on the 


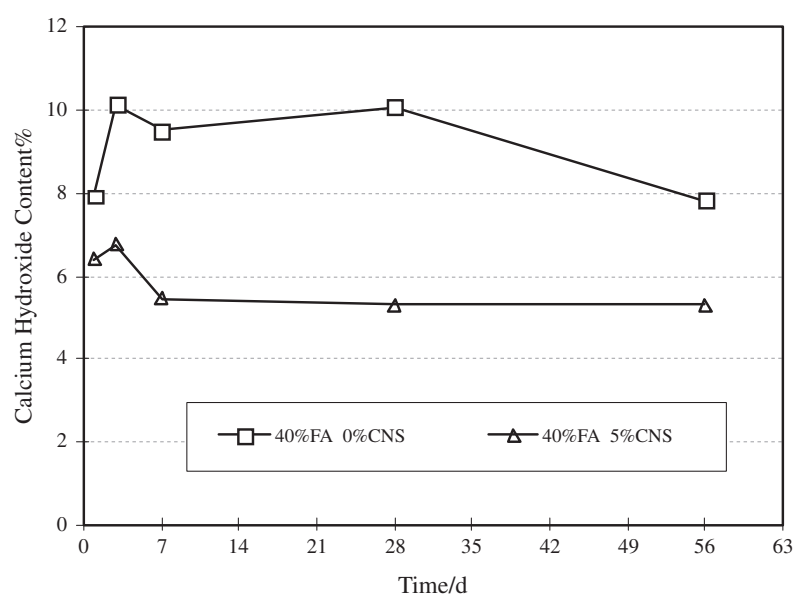

Fig. 15. $\mathrm{Ca}(\mathrm{OH})_{2}$ content vs. time.

mechanical properties of fly ash mortars was investigated and factors affecting the strength evolution, i.e., CNS dosage, fly ash types and replacement levels, were analyzed. The influence of CNS on the strength evolution of fly ash mortar was studied and it was also correlated to the physiochemical properties of CNS.

\subsubsection{CNS-fly ash mortar strength - effect of CNS dosage}

Results showing the effects of CNS dosage on the strength gain of FA1 mortars are shown in Fig. 14.

For $0 \%$ CNS mortars at each fly ash replacement level, $R$ was less than $100 \%$ and increased with curing ages. This indicates that fly ash greatly reduces the strength gain of cement mortar, especially at early ages. When CNS was added, the early-age strength ( $1 \mathrm{~d}$, $3 \mathrm{~d}$, and $7 \mathrm{~d}$ ) was enhanced. However, by 3 months $(3 \mathrm{~m})$ the strengths of CNS-fly ash mortars were exceeded by those of fly ash mortars without CNS, indicating that CNS had negative effects at later ages. Apart from the hydration hindrance effect of CNS on cement at later ages shown in Section 3.4.1, another critical characteristic of CNS-added fly ash-cement systems, namely the high $\mathrm{Ca}(\mathrm{OH})_{2}$-consumption capacity of CNS, has rarely been taken into consideration to address this trend in strength evolution. Whether the extra $\mathrm{Ca}(\mathrm{OH})_{2}$ consumption by $\mathrm{CNS}$ at early ages will adversely affect the later-age strength evolution introduced by the pozzolanic reaction of fly ash is unknown. Therefore, TGA was used to determine the $\mathrm{Ca}(\mathrm{OH})_{2}$ contents of the CNS-fly ash-cement systems.

It is shown in Fig. 15 that in fly ash-cement pastes, at each age, the $\mathrm{Ca}(\mathrm{OH})_{2}$ content of the $5 \%$ CNS paste was lower than that of the $0 \%$ CNS paste. The greater $\mathrm{Ca}(\mathrm{OH})_{2}$ consumption of $5 \% \mathrm{CNS}$-added paste is due to the additional pozzolanic reaction of CNS. Moreover, it is interesting to note that more $\mathrm{Ca}(\mathrm{OH})_{2}$ was consumed in the $0 \%$ CNS fly ash paste at later ages (28-56 d), indicating that further pozzolanic reaction of fly ash had occurred. The direct measurement of the pozzolanic reaction degree of fly ash at 7 months showed that only half as much fly ash is hydrated in CNS-added paste as that of the $0 \%$ CNS paste. Thus a lack of calcium hydroxide at later ages, which results in a lower hydration degree of fly ash, can be a contributing factor to the reduced rate in compressive strength gain of fly ash-cement systems with CNS at later ages.

Plots in Fig. 14 also show that the degree of early-age strength improvement is determined by the fly ash replacement ratio and
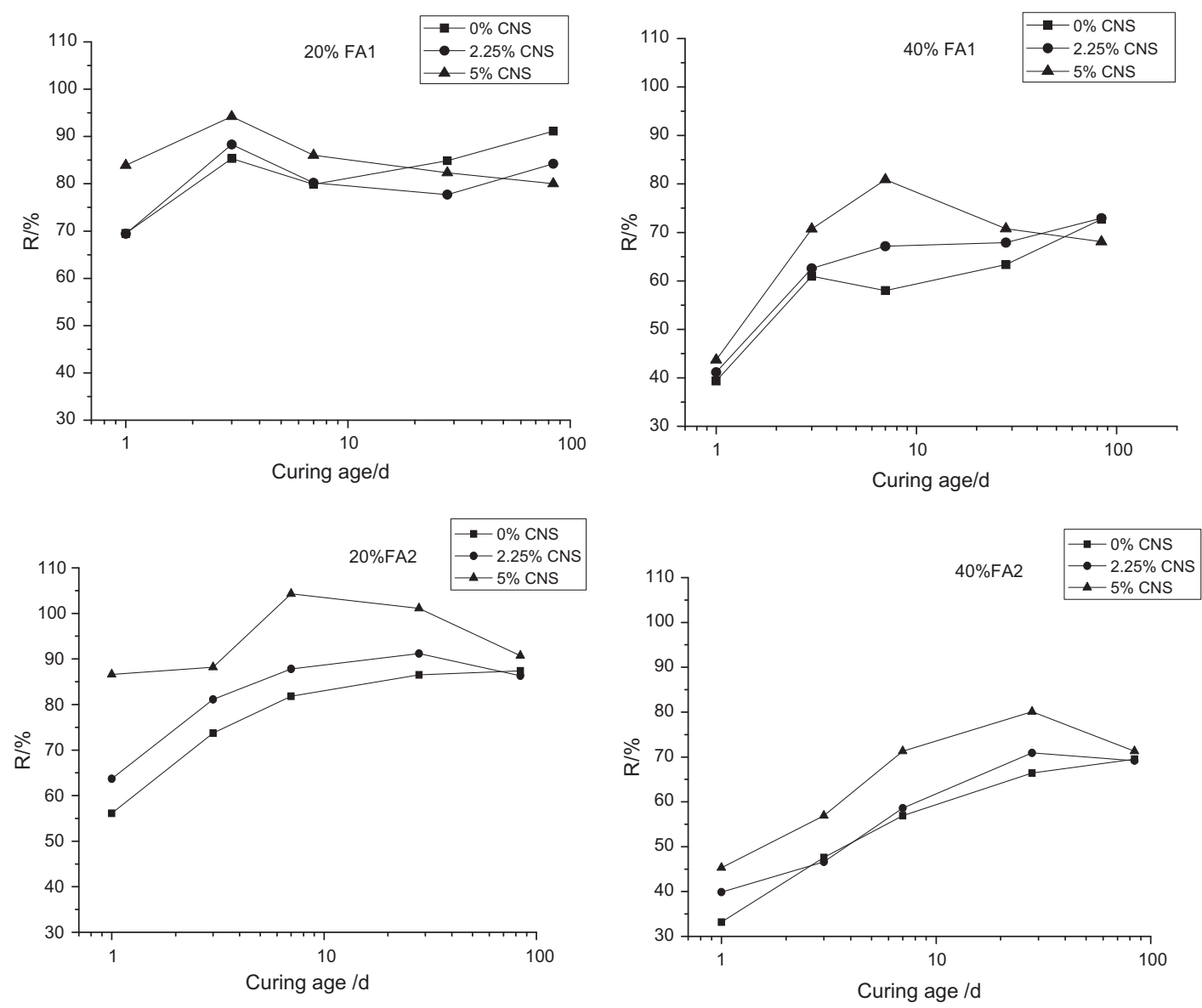

Fig. 16. Comparison of the effects of CNS-10 nm on the mechanical properties of FA1 and FA2 cement mortars. 
CNS dosage. The improvement in strength by CNS compared to fly ash mortars without CNS was more significant for $40 \%$ and $60 \%$ fly ash mortars than for $20 \%$. Considering the water volume fraction differences of the three mortars are very slight, i.e., $25.9 \%, 25.6 \%$ and $25.3 \%$ for $20 \%, 40 \%$ and $60 \%$ fly ash replacement mortars, respectively, results indicate that CNS is more effective for the activation of high fly ash replacement systems. Regarding the effect of CNS dosage on strength evolution, it is shown that 5\% CNS can improve the strength two times as much as $2.25 \% \mathrm{CNS}$ at early ages. It has been widely accepted that cement hydration is a type of dissolution-precipitation process and the nucleation rate is linearly proportional to the nucleating surface content [41], thus a higher CNS content results in a higher early age strength. It is also shown that the higher the dosage of CNS, the greater the reduction in strength at later ages. This may be due to greater $\mathrm{Ca}(\mathrm{OH})_{2}$ consumption at early ages, as well as a greater hydration hindrance effect of CNS at later ages.

\subsubsection{CNS-fly ash mortar strength - effect of FA type}

As aforementioned, the chemical and mineralogical compositions of the two fly ashes are different. The difference was also demonstrated by their effect on the mechanical properties of mortar. The strength enhancing effects of CNS-10 nm on FA1 and FA2 were compared. It is shown in Fig. 16 that when compared to the FA1 mortar, the compressive strength of FA2 was less than that of FA1 in the first $7 \mathrm{~d}$ of curing. After $7 \mathrm{~d}$, the mechanical properties of FA1 mortars were better developed than those of FA2. This may be attributed to the differences in $\mathrm{CaO}$ and amorphous content of the fly ashes, as described in the material characterization section. The chemical composition and the content of the glass phase are important factors for the pozzolanic reactivity of fly ash - a higher $\mathrm{CaO}$ content can lead to high early-age reactivity [4] and a higher amorphous content can supply more sources for pozzolanic reaction at later ages.

It can be observed that the compressive strength of $5 \%$ CNS, $20 \%$ FA2 mortar was greater than that of the control at $7 \mathrm{~d}$ and $28 \mathrm{~d}$. At the same time, it is shown in Fig. 16 that the strength enhancing effect of CNS was sustained longer in FA2 mortar than in FA1 mortar. All these features may be due to the differing characteristics of the fly ashes.

Similar to what was observed in the FA1 mortars, the strength enhancing effect of CNS decreased at later ages in the FA2 mortar, as well. The $56 \mathrm{~d}$ compressive strengths of CNS-added FA2 mortars are comparable to those of non-CNS mortars.

\section{Conclusions}

The following conclusions can be drawn from the present study:

1. The addition of CNS greatly enhances the hardening process of fly ash-cement pastes. A paste with $40 \%$ fly ash replacement and 5\% CNS addition exhibited comparable initial and final setting times as plain cement paste.

2. The incorporation of fly ash and CNS each increase the viscosity of cement pastes. However, there exists a threshold value for the CNS dosage above which the viscosities of fly ash-cement pastes become equal to or less than those of cement pastes without fly ash. The incorporation of fly ash offsets the decrease in flowability of mortars caused by CNS.

3. The early-age compressive strength of fly ash-cement mortars can be greatly improved by the addition of CNS: the higher the dosage, the greater the improvement. However, CNS adversely affects strength gain at later ages: the higher the dosage, the greater the reduction in rate of strength gain.
4. Calcium hydroxide consumption by the CNS at early ages and the hydration hindrance effect of CNS on cement at later ages are contributing factors to the gradual decrease in rate of strength gain exhibited by fly ash-cement systems at later ages.

The benefits of fly ash and CNS can help counteract the shortcomings of each other, however, the influence of CNS on the hydration of this system at later ages, as well as its influence on the resulting gel properties need more research. Methods of mitigating the hydration hindrance effect of CNS on cementitious materials at later ages are also needed.

\section{Acknowledgments}

The authors would like to thank the financial support from Infrastructure Technology Institute at Northwestern University for Grant DTRT06-G-0015.

The first author would also like to thank China Scholarship Council for its financial support during his study at Northwestern University.

\section{References}

[1] Şahmaran M, Yaman İÖ, Tokyay M. Transport and mechanical properties of self consolidating concrete with high volume fly ash. Cem Concr Comp 2009;31(2):99-106.

[2] Bentz D, Ferraris C. Rheology and setting of high volume fly ash mixtures. Cem Concr Comp 2010;32(4):265-70.

[3] Lam L, Wong Y, Poon C. Degree of hydration and gel/space ratio of high-volume fly ash/cement systems. Cem Concr Res 2000;30(8):747-56.

[4] Sakai E, Miyaharab S, Ohsawa S, Lee S, Daimon M. Hydration of fly ash cement. Cem Concr Res 2005;35(6):1135-40.

[5] Ati C. Heat evolution of high-volume fly ash concrete. Cem Concr Res 2002;32(5):751-6.

[6] Payá J, Monzó J, Borrachero M, Peris-Mora E. Mechanical treatment of fly ashes: Part IV. Strength development of ground fly ash-cement mortars cured at different temperatures. Cem Concr Res 2005;30(4):543-51.

[7] Criado M, Jiménez A, Palomo A. Effects of sodium sulfates on the alkali activation of fly ash. Cem Concr Comp 2010;32(8):589-94.

[8] Babaian P, Wang K, Mishulovich A, Shah SP. Effect of mechanochemical activation on reactivity of cement kiln dust-fly ash systems. ACI Mater J 2003;100(1):55-62.

[9] Goñi S, Guerrero A, Luxán M, Macías A. Activation of the fly ash pozzolanic reaction by hydrothermal conditions. Cem Concr Res 2003:33(9):1399-405.

[10] Wang K, Shah S, Mishulovich A. Effects of curing temperature and $\mathrm{NaOH}$ addition on hydration and strength development of clinker-free CKD-fly ash binders. Cem Concr Res 2004;34(2):299-309.

[11] Nazari A, Riahi S. The effects of $\mathrm{SiO}_{2}$ nanoparticles on physical and mechanical properties of high strength compacting concrete. Comp Part B: Eng 2011;42(3):570-8.

[12] Shih J, Chang T, Hsiao T. Effect of nanosilica on characterization of Portland cement composite. Mater Sci Eng: A 2006;424(1-2):266-74.

[13] Li H, Xiao H, Yuan J, Ou J. Microstructure of cement mortar with nano-particle. Comp: Part B 2004;35(2):185-9.

[14] Zhang M, Islam J. Use of nano-silica to reduce setting time and increase early strength of concretes with high volumes of fly ash or slag. Constr Build Mater 2012;29:573-80.

[15] Zhang M, Islam J, Peethamparan S. Use of nano-silica to increase early strength and reduce setting time of concretes with high volumes of slag. Cem Concr Comp 2012;34(5):650-62.

[16] Li G. Properties of high-volume fly ash concrete incorporating nano- $\mathrm{SiO}_{2}$. Cem Concr Res 2004;34(6):1043-9.

[17] Thomas JJ, Jennings HM, Chen JJ. Influence of nucleation seeding on the hydration mechanisms of tricalcium silicate and cement. J Phys Chem 2009;113(11):4327-34.

[18] Gundogdu D, Pekmezci BY, Atahan HN. Influence of nanosilica on the mechanical properties of mortars containing fly ash. In: Brameshuber E, editor. Internal RILEM conference on materials science. Additions Improving Properties of Concrete (AdIPoC), vol. 3, 2010. p. 345-54.

[19] Sobolev K, Flores I, Hermosillo R, Torres-Martinez LM. Nanomaterials and nanotechnology for high-performance cement composites. In: Sobolev K, Shah SP, editors. Nanotechnology of concrete: recent developments and future perspectives, 2010. p. 93-120.

[20] Berra M, Carassiti F, Mangialardi T, et al. Effects of nanosilica addition on workability and compressive strength of Portland cement pastes. Constr Build Mater 2012;35:666-75.

[21] Hou P, Kawashima S, Kong D, et al. Modification effects of colloidal nanoSiO on cement hydration and its gel property. Comp Part B: Eng, in press. 
[22] Hou P, Wang K, Qian J, Kawashima S, Kong D, Shah SP. Effect of colloidal nanosilica on fly ash hydration. Cem Concr Comp 2012;34:1095-103.

[23] MK Impex Corporation, Canada. <http://www.mknano.com/item-details. asp? catDisp=2\&itemid=80\&id $=10>$.

[24] ASTM C618-08. Standard specification for coal fly ash and raw or calcined natural pozzolan for use in concrete. West Conshohocken (PA, USA): ASTM International; 2008. p. 4.

[25] Papadakis VG. Effect of fly ash on Portland cement systems: Part II. Highcalcium fly ash. Cem Concr Res 2000;30(10):1647-54.

[26] Wang S, Ma Q, Zhu Z. Characteristics of coal fly ash and adsorption application. Fuel 2008;87(15-16):3469-73.

[27] ASTM C191-08. Standard test methods for time of setting of hydraulic cement by vicat needl. West Conshohocken (PA, USA): ASTM International; 2008. p. 8.

[28] Saak A, Jennings H, Shah SP. The influence of wall slip on yield stress and viscoelastic measurements of cement paste. Cem Concr Res 2001;31(2):205-12.

[29] ASTM C230-08. Standard specification for flow table for use in tests of hydraulic cement. West Conshohocken (PA, USA): ASTM International; 2008. p. 12.

[30] ASTM C109-08. Standard test method for compressive strength of hydraulic cement mortars (using 2-in. or [50-mm] cube specimens). West Conshohocken (PA, USA): ASTM International; 2008. p. 12

[31] Scrivener K. Backscattered electron imaging of cementitious microstructures: understanding and quantification. Cem Concr Comp 2004;26(8):935-45.

[32] Senff L, Labrincha JA, Ferreira VM, Hotza D, Repette WL. Effect of nano-silica on rheology and fresh properties of cement pastes and mortars. Constr Build Mater 2009;23(7):2487-91.
[33] Ferron R. Formwork pressure of self-consolidating concrete: influence of flocculation mechanisms, structural rebuilding, thixotropy and rheology. $\mathrm{PhD}$ thesis, Evanston (IL): Northwestern University; 2008

[34] Krieger I, Dougherty T. A mechanism for non-Newtonian flow in suspensions of rigid spheres. Trans Soc Rheol 1959;3(1):137-52.

[35] Papo A, Piani L, Ricceri R. Rheological properties of very high-strength Portland cement pastes: influence of very effective superplasticizers. Int J Chem Eng 2010. http://dx.doi.org/10.1155/2010/682914.

[36] Thomas J, Jennings $\mathrm{H}$. The nanostructure of low- $-\mathrm{CO}_{2}$ concrete for a sustainable infrastructure, 2010. [Report on year 1 activities and recommendations for future work, A Scientific Collaboration Between Lafarge Center for Research (LCR) and Northwestern University (NWU)].

[37] Kontoleontos F, Tsakiridis P, Marinos A, et al. Influence of colloidal nanosilica on ultrafine cement hydration: physicochemical and microstructural characterization. Constr Build Mater 2012;3:347-60.

[38] Zyganitidis I, Stefanidou M, Kalfagiannis N, Logothetidis S. Nanomechanical characterization of cement-based pastes enriched with $\mathrm{SiO}_{2}$ nanoparticles. Mater Sci Eng B 2011;176(19):1580-4.

[39] Gaitero JJ. Multi-scale study of the fibre-matrix interface and calcium leaching in high performance concrete. Ph.D thesis, Spain; 2008.

[40] Mondal P. Nanomechanical properties of cementitious materials. PhD thesis, USA: Evanston, Northwestern University; 2008.

[41] Givi AN, Rashid SA, Aziz FN, Salleh MA. Experimental investigation of the size effects of $\mathrm{SiO}_{2}$ nano-particles on the mechanical properties of binary blended concrete. Comp Part B 2010;41:673-7. 